\title{
Are animal-related injuries in rural areas a social problem? A survey from Poland
}

\author{
Aneta Neskoromna-Jędrzejczak', Katarzyna Bogusiak', Anna Kasielska-Trojan², \\ Bogusław Antoszewski \\ ${ }^{1}$ Department of Craniomaxillofacial and Oncological Surgery, Medical University in Lodz, Lodz, Poland \\ 2 Plastic, Reconstructive and Aesthetic Surgery Clinic, Medical University in Lodz, Lodz, Poland
}

Bogusiak K, Neskoromna-Jędrzejczak A, Kasielska-Trojan A, Antoszewski B. Are animal-related injuries in rural areas a social problem? A survey from Poland. Ann Agric Environ Med. 2017; 24(3): 392-395. doi: 10.26444/aaem/74493

\begin{abstract}
Objective. The aim of this study was to analyze the mechanisms of animal-related injuries in Polish rural areas, and to evaluate the effects of such injuries on subjects' health and social life.

Materials and method. Data concerning animal-related injuries were collected from 102 patients ( 45 females and 57 males, mean age $45.01 \pm 11.4$ years) on the basis of a questionnaire. The study was conducted in the rural area of central Poland. Moreover, to assess the severity of injuries to the head and neck region, the Facial Injury Severity Scale (FISS) was applied. Results. The most commonly affected body areas are the upper and lower limbs, which explains the fact that most subjects do not recognize the injury-related deformity as an aesthetic defect.Statistical correlations were observed in several aspects, amongst others:

- women were significantly more likely than men to consider undergoing surgical procedures to eliminate/reduce posttraumatic deformities and scars $(p<0.05)$;

- injury-related deterioration in appearance resulted in limitations of patients' social life $(p<0.0001)$.
\end{abstract}

\section{Key words}

animals, bites, animal-related injuries

\section{INTRODUCTION}

About 1.3 billion people are employed in the agricultural sector worldwide. According to a report by the International Labour Organization, more than 150,000 of them die each year during work, and an unknown number suffer from injuries, also from animal-related injuries [1]. In the USA, where statistical information associated with animal-related injuries is best documented, about 1.3 million of such injuries are reported annually [2]. Recent studies from different countries have presented that about $10 \%$ of farmers have had an accident in the past year [3-6]. Although the frequency and types of animal-related injuries differ between the regions of the world, it is known that such injuries are more common among people living in agricultural areas [7]. Animal-related injuries on farms and in rural areas are also more severe than in urban areas, which is a consequence of the high percentage of traumas caused by livestock animals (cattle, pigs, horses) and wild animals (boars, bears etc.) [7]. In 2013, in rural areas in Poland, 1,807 people suffered from animal-relatedinjuries [8]. In comparisn, in 2006, the number of such accidents was much higher and reached 2,620 injuries. This means that the number of animal-relatedinjuries in agriculture decreased by 813 cases in $2006-2013$. This could be the result of training programmes provided by the Agricultural Social Insurance Fund [8]. It should be emphasized that the percentage of fatal animal-related injuries during all the mentioned periods remains at a relatively low level - about $0.10 \%-0.21 \%$ [9]. Similarly, in Europe, livestock-related

Address for correspondence: Katarzyna Bogusiak, Department of Craniomaxillofacial and Oncological Surgery, University Hospital No 1, Lodz, Poland

E-mail: katarzyna.bogusiak@gmail.com

Received: 15 December 2015; accepted: 23 August 2016; first published: April 2017 injuries are frequent but usually not severe, and fatalities caused by animals are mentioned on the $5^{\text {th }}$ place of causes of death in agriculture [10].

Studies have been conducted for better understanding the main causes of accidents in agriculture [11-13]. According to Swedish research, there are three defined factors that influence risk and safety during contact and working with animals: the human (handler), the animal (cattle), and the facilities. Correlation among them presents an influence on the potential risks of injury [11]. On the basis of Finnish research, an assumption was made that the chain of causation is different for fatal and non-fatal injuries [13]. Some authors emphasize that despite the large number of documented animal-related injuries, there is still a small number of publications dealing with this problem in scientific literature [11].

The aim of this study was to analyze the mechanisms of animal-related injuries in Polish rural areas, and to evaluate the effects of such injuries on subjects' health and social life.

\section{MATERIALS AND METHOD}

Examined population. The questionnaire studies were carried out by doctors in the rural area of Lodz province in central Poland $(2,541,832$ inhabitants, about $14 \%$ involved in agriculture in 2009) who gave a history of at least one animal-related injury, and who consented to complete the questionnaire [14]. The data were collected from a group of 102 people (44.1\% females; mean age 45.01 years (SD 11.4 years); $55.9 \%$ were males, mean age 45.7 years (SD 11.9 years). The population included subjects with the following education: primary (12.7\%), vocational (33.3\%), secondary (36.3\%), incomplete higher (16.7\%) and higher (1\%). All respondents 
answered the questions related to their demographic data, attitude towards animals ('definitely positive', 'rather positive', 'no opinion', 'rather negative' and 'definitely negative'), presence of animals in their farm, number of animal-related injuries and the circumstances. Respondents were also asked if they took into consideration undergoing surgical procedures to eliminate/reduce posttraumatic deformities and scars. Moreover, in the case of subjects who underwent facial injury, the Facial Injury Severity Scale (FISS) score was assessed [15]. The possible answers for most of the survey's questions were 'definitely yes', 'rather yes', 'I do not have opinion', 'rather no' and 'definitely no'.

Statistical analysis. The data were compared by using the following statistical tests: Mann-Whitney, Spearman correlation coefficient, Kruskal-Wallis and chi-square. To determine specific differences, standardized residuals were calculated. A values lower than -1.96 or higher than 1.96 indicated that the answers appeared significantly less frequently.

\section{RESULTS}

More than half of the respondents (53\%) had only one animalrelated injury, but there were 4 subjects who reported 4 injuries and one who had 5 such incidents. Statistical analysis did not reveal significant correlations between the number of injuries and: respondents' gender $(\mathrm{p}=0.6383)$, attitude towards animals $(\mathrm{p}=0.5079)$, time of having an animal (in years) $(\mathrm{R}=0.0817, \mathrm{p}=0.4142)$, being under the influence of alcohol when sustaining the injury $(p=0.6806)$, and awareness of the fact that alcohol raises the risk of such injury $(\mathrm{p}=0.0503)$. It was also checked whether the respondents who suffered from a single injury differed from those who had more incidents from the above-mentioned aspects. It was found that subjects who had single injury significantly more frequently reported awareness of the fact that alcohol raises the risk of such injury $(p=0.0126)$. However, no correlation was found between being under the influence of alcohol when sustaining the injury and awareness that it increases the risk of such an incident $(\mathrm{p}=0.06)$.

Most of the respondents reported that an injury-related deformity did not influence the appearance of the affected body area, their social and occupational activities, nor life quality. Female and male groups did not differ in these aspects; however, women were significantly more likely than men to consider undergoing surgical procedures to eliminate/ reduce post-traumatic deformities and scars $(\mathrm{p}=0.013)$.

Further analysis concerned whether impaired appearance influenced social and occupational activities and life quality, and which factors were related to the decision to undergo surgical procedures to correct deformity. The questionnaire answers were transcoded to the numeric values, and Spearman coefficients calculated. It was found that respondents who reported injury-related deterioration in their appearance were more prone to limit their social life. Moreover, those who recognized their life quality as worse than before the injury, were more likely to undergo surgical correction (Tab. 1).

Further analysis evaluated how animal-related injury influenced respondents' general health/functioning. For the purpose of this analysis, subjects were divided into
Table 1. Correlations between impaired appearance and social and occupational activities and life quality, and factors related to the decision of undergoing surgical procedures to correct deformities

\begin{tabular}{llll}
\hline Injury-related & affected social life & $\mathrm{R}=0.4321$ & $\mathrm{P}<0.0001$ \\
\cline { 2 - 4 } $\begin{array}{l}\text { deterioration in } \\
\text { appearance versus: }\end{array}$ & affected occupational activity & $\mathrm{R}=0.1358$ & $\mathrm{P}=0.1736$ \\
\cline { 2 - 4 } $\begin{array}{l}\text { onsider undergoing } \\
\text { surgery to eliminate/ } \\
\text { reduce post-traumatic } \\
\text { deformities and scars }\end{array}$ & deterioration in appearance & $\mathrm{R}=0.0838$ & $\mathrm{P}=0.4022$ \\
\cline { 2 - 4 } \begin{tabular}{l} 
versus: \\
\cline { 2 - 4 }
\end{tabular} & affected social life & $\mathrm{R}=-0.0292$ & $\mathrm{P}=0.7707$ \\
\cline { 2 - 4 } & affected life-quality & $\mathrm{R}=0.1266$ & $\mathrm{P}=0.2048$ \\
\hline
\end{tabular}

Spearman correlation coefficients

groups in relation to the animal that caused the injury (pets: dogs, cats and farm animals; big animals: horses/mares or bulls/cows; small: pigs, goats or sheep, etc.). However, some respondents had multiple injuries caused by different animals, which implicated their inclusion to more than one group. It was found that those who suffered from petrelated injury significantly less frequently reported that the injury affected their general health/functioning, while big farm animal-related injury was more commonly associated with deterioration of health/functioning. Additionally, the respondents injured by small farm animals, more frequently than others, did not have opinion about the influence of the injury on their general health/functioning (Tab. 2).

Table 2. Correlation between general health/functioning and type of animal that caused the injury

\begin{tabular}{lccccccc}
\hline & \multicolumn{5}{c}{ Injury caused by: } \\
\cline { 2 - 7 } & \multicolumn{5}{c}{ Pets } & \multicolumn{5}{c}{ Small farm animals } & Big farm animals \\
\hline $\begin{array}{l}\text { Injury affected general } \\
\text { health/functioning: }\end{array}$ & $\mathrm{n}(\%)$ & Rs & $\mathrm{n}(\%)$ & Rs & $\mathrm{n}(\%)$ & $\mathrm{Rs}$ \\
\hline Definitely yes & $3(8.3 \%)$ & -3.22 & $2(15.4 \%)$ & -1.10 & $27(42 \%)$ & 3.74 \\
\hline Rather yes & $15(41.7 \%)$ & 0.41 & $1(7.7 \%)$ & -2.46 & $28(44 \%)$ & 1.20 \\
\hline No opinion & $6(16.7 \%)$ & 0.15 & $8(61.5 \%)$ & 4.78 & $4(6 \%)$ & -3.21 \\
\hline Rather no & $9(25 \%)$ & 2.51 & $2(15.4 \%)$ & 0.24 & $4(6 \%)$ & -2.52 \\
\hline Definitely no & $3(8.3 \%)$ & 1.89 & $0(0 \%)$ & -0.73 & $1(2 \%)$ & -1.30 \\
\hline$P$ & & chi-square $=44.3098, \mathrm{p}<0.0001$ & \\
\hline
\end{tabular}

Rs - standardised residuals

Body areas injured during the incidents were as follows (some respondents had more than one injury or more than one site injured during a single accident): face (26 subjects), upper limb $(n=34)$, lower limb $(n=40)$ and trunk $(n=17)$. The type of animal that caused the injury did not appear to correlate with the affected areas $(\mathrm{p}>0.05)$. Similarly, no association was found between FISS score and subjective assessment of respondents' deterioration in: appearance of the affected body area $(\mathrm{R}=-0.1086 ; \mathrm{p}=0.6055)$, social life $(\mathrm{R}=-0.0545 ; \mathrm{p}=0.7959)$,occupational activity $(\mathrm{R}=0.0226$; $\mathrm{p}=0.9148)$, and decision to undergo surgical correction $(\mathrm{R}=-0.1785 ; \mathrm{p}=0.3932)$.

In the examined group, 20 subjects reported that the animal-related injury resulted in a facial scar, but there was no correlation between the scar's length and appearance of the affected body area $(\mathrm{R}=-0.2693 ; \mathrm{p}=0.251)$, social $(\mathrm{R}=0.0184$; $\mathrm{p}=0.9385)$ and occupational $(\mathrm{R}=-0.0504 ; \mathrm{p}=0.8330)$ activities and willing to undergo surgical scar correction $(\mathrm{R}=-0.2711$; $\mathrm{p}=0.2477)$. 


\section{DISCUSSION}

Most animal-related injuries were not severe and patients with such traumas usually did not seek medical help; therefore, these cases were not recorded in the statistics [16-18]. This fact also explains the very low percentage of patients with animal-related injuries in the total number of trauma patients. Different types of injuries may cause specific consequences, e.g. concomitant blunt injuries, large facial deformities, bacterial complications, and the possibility of transmitting zoonoses $[7,19]$. The severity of the animalrelated trauma, however, depended on many different factors.

The presented study revealed that respondents' gender and attitude towards animals did not relate to the number of animal-related injuries. Alcohol intoxication before the accident was not associated with a higher number of analyzed type of traumas. People who suffered from such accident only once, more frequently reported awareness of the fact that alcohol raises the risk of animal-related injuries.

Data concerning gender differences in the injury rate presented in large epidemiological researches, is not consistent $[2,7]$. In studies concerning traumas in agriculture, males predominated [20]. Alcohol consumption was a variable that was not analysed in large studies on accidents with animals in agriculture. However, in other studies concerning animal-related injuries, especially caused by dogs, alcohol consumption is one of the risk factor of animal attack [21]. The percentage of alcohol intoxicated patients after different traumas is higher than that observed in the current study, excluding work accidents [22]. Intoxicated people with isolated head injuries, alcohol may improve prognosis and mortality rate by its neuroprotective feature, even though the severity of such injuries is much higher than in sober people [23-29]. In cases of polytrauma injuries, their effect proved to be negative [30-32], and also increased the number of complications [25, $26,32]$. Moreover, it impairs psychomotor performance and concentration, causing a decrease in criticism and the ability of perception as well as proper judgement. This is especially essential when considering the circumstances and risk factors of accidents occurrence, including animal-related injuries. Also, it was proved that alcohol consumption reduced the usage of injury prevention measures [33].

Many authors emphasize that most of the injuries associated with animal contact are not severe and ambulatory treatment is sufficient $[7,34,35]$.The majority of more serious injuries are caused by large animals, especially in agriculture (pigs, horses and cows attacks) $[7,20,36,37]$.The injured areas depended mainly on the animal that caused the injury, and indirectly the victim's place of residence (urban/rural areas) [7, 35, 38]. Attacks by dogs were mainly connected with bites on the lower and upper extremities [39]. In children, the head and neck area was even more frequently attacked by dogs than in adults $[40,41]$, whereas, in agriculture multiple injuries were more common $[7,20]$.

Similar to the presented study, analysis of the anatomic location of injury revealed that the areas most frequently affected were the lower and upper limbs. Surprisingly, the analysis of injured areas did not reveal any correlation with the animal that caused the injury. Post-traumatic deformity did not have a negative influence on respondents' appearance assessment, social and occupational activities, nor on the quality of life. Pet-related injuries less frequently had a negative influence on the general health of injured owners, while livestock animals caused injuries that more commonly impaired the general functioning of victims.

Other authors also observed that a small percent of injured farmers had had contact with medical stuff, ambulatory consultation, or had been hospitalized [20]. Such an attitude towards seeking medical help, as well as late presentation following injury, is responsible for the increased rate of complications, post-traumatic deformity and work disability $[42,43]$. In the Swedish survey most, farmers declared that they are aware of the danger of working with animals and the fact that safety during interaction with animals is an important and relevant issue. Nevertheless, they admitted that safety rules are often forgotten and not prioritized and though a majority of accidents could be prevented $[11,44]$.

\section{CONCLUSIONS}

To sum up, the presented study is the first in local literature and one of the few among worldwide researches dealing with the problem of agricultural animal-related injuries from the aspects of the mechanisms and social consequences. It was found that the most commonly affected body areas are the upper and lower limbs and, due to this fact, most subjects did not recognize the injury-related deformity as an aesthetic defect. However, in cases where the appearance was impaired because of facial injury, social life was limited and affected the quality of life, seemed to be the crucial decisive factor forundergoing surgical correction. Moreover, the study shows that big farm animals caused injuries recognized as more severe from the aspect of general health and functioning.

\section{REFERENCES}

1. International Labour Organization. Agriculture: a hazardous work www.ilo.org Accesse dat 25th of Dec 2014.

2. Adams A, Suton J, Elixhauser A. Emergency Department Visits and Hospitalization Associated with Animal Injuries. 2009. HCUP Statistical Brief \#134. May 2012

3. Reiling J. Agricultural injuries in Norway. J Agromedicine. 1997; 4: 285-294.

4. McCurdy SA, Carroll DJ. Agricultural injury. Am J Ind Med. 2000; 38: 463-480.

5. Solomon C. Accidental injuries in agriculture in the UK. Occup Med. 2002; 52: 461-466.

6. Browning SR, Truszczynska H, Reed D, McKnight RH. Agricultural injuries among older Kentucky farmers: the farm family health and Hazard Surveillance study. Am J Ind Med. 1998; 33: 341-353.

7. Nogalski A, Jankiewicz L, Ćwik G, Karski J, Matuszewski Ł. Animal related injuries treated at the Department of Trauma and Emergency Medicine, Medical University of Lublin. Ann Agric Environ Med. 2006; 13: 57-61.

8. Agricultural Social Insurance Fund. www.krus.gov.pl. Accesse dat 25th of Dec 2014.

9. Statement of accidents at work and occupational diseases of farmers in 2013.Kasa Rolniczego Ubezpieczenia Społecznego (KRUS), ang. Agricultural Social Insurance Fund (ASIF). Warsaw 2014.

10. The European Agency for Safety and Health at Work. https://osha. europa.eu Accesse dat 25th of Dec 2014

11. Lindahl C, Lundqvist P, Norberg AL. Swedish dairy farmers' perceptions of animal-related injuries. J Agromedicine. 2012; 17: 364-376.

12. Casey GM, Grant AM, Roerig DS, Boyd J, Hill M, London M, Gelberg KH, Hallman E., Pollock J. Farm worker injuries associated with cows. New York State 1991-1996. AAOHN J. 1997; 45: 446-450.

13. Salminen S, Saari J, Saarela KL, Rasanen T. Fatal and nonfatal occupational accidents - identical versus differential causation. Safety Sci. 1992; 15: 109-118. 
14. Neskoromna-Jędrzejczak A, Bogusiak K, Kasielska-Trojan A, Antoszewski B. Questionnaire: "Animal-related injuries in rural areas".

15. Bagheri SC, Dierks EJ, Kademani D, Holmgren E, Bell RB, Hommer L, Potter BE. Application of a facial injury severity scale in craniomaxillofacial trauma. J Oral Maxillofac Surg. 2006; 64(3): 408-14.

16. Björnstig U, Eriksson A, Ornehult L. Injuries caused by animals. Injury 1991; 22(4): 295-298.

17. Langley RL, Morrow WE. Deaths resulting from animal attacks in the United States. Wilderness Environ Med. 1997; 8(1): 8-16.

18. Morris JA Jr, MacKenzie EJ, Damiano AM, Bass SM. Mortality in trauma patients: the interaction between host factors and severity. J Trauma. 1990; 30(12): 1476-82.

19. Raghavan M. Fatal dog attacks in Canada, 1990-2007. Can Vet J. 2008; 49(6): 577-581.

20. Svendsen K, Aas O, Hilt B3. Nonfatal occupational injuries in Norwegian farmers. Saf Health Work. 2014; 5(3): 147-51.

21. Lathrop SL. Animal-caused fatalities in New Mexico, 1993-2004. Wilderness Environ Med. 2007; 18(4): 288-92.

22. Borowska-Solonynko A, Dąbkowska A, Raczkowska Z, Kwietniewski W. The effect of alcohol consumption on the severity of injuries, prognosis and mortality - a review of literature. Arch Med Sad Kryminol. 2012; 62: 47-54.

23. Porter RS. Alcohol and injury in adolescents. Pediatr Emerg Care. 2000; 16(5): 316-320.

24. Yaghoubian A, Kaji A, Putnam B, de Virgilio N, de Virgilio C. Elevated Blood Alcohol Level May Be Protective of Trauma Patient Mortality. Am Surg. 2009; 75(10): 950-953.

25. Salim A, Ley EJ, Cryer HG, Margulies DR, Ramicone E, Tillou A. Positive Serum Ethanol Level and Mortality in Moderate to Severe Traumatic Brain Injury. Arch Surg. 2009; 144(9): 865-871.

26. Plurad D, Demetriades D, Gruzinski G, Preston C, Chan L, Gaspard $\mathrm{D}$, et al. Motor vehicle crashes: the association of alcohol consumption with the type and severity of injuries and outcomes. J Emerg Med. 2010; 38(1): 12-17.

27. Choi Y, Jung K, Eo E, Lee D, Kim J, Shin D, et al. The relationship between alcohol consumption and injury in ED trauma patients. Am J Emerg Med. 2009; 27(8): 956-960.

28. Johnston JJE, McGovern SJ. Alcohol related falls: an interesting pattern of injuries. J Emerg Med. 2004; 21(2): 185-188.

29. Crocker P, Zad O, Milling T, Lawson KA. Alcohol, bicycling, and head and brain injury: a study of impaired cyclists' riding patterns R1. Am J Emerg Med. 2010; 28(1): 68-72.
30. Moore EE. Alcohol and trauma: The perfect storm. J Trauma. 2005; 59(3): S53-S56.

31. Ranzer MJ, Chen L, DiPietro LA. Fibroblast function and wound breaking strength is impaired by acute ethanol intoxication. Alcohol Clin Exp Res. 2011; 35(1): 83-90.

32. Brattstrom O, Granath F, Rossi P, Oldner A. Early predictors of morbidity and mortality in trauma patients treated in the intensive care unit. Acta Anaesthesiol Scand. 2010; 54(8): 1007-1117.

33. Swearingen A, Ghaemmaghami V, Loftus T, Swearingen CJ, Salisbury $\mathrm{H}$, Gerkin RD, et al. Extreme blood alcohol level is associated with increased resource use in trauma patients. Am Surg. 2010; 76(1): 20-24.

34. Zhang QB, Zhang B, Zhang ZQ, Chen Q. The epidemiology of cranio-facial injuries caused by animals in southern-central China. J Craniomaxillofac Surg. 2012; 40(6): 506-9.

35. Caglayan K, Celik A, Ozkan OF, Celik AS, Koksal N, Altinli E. Large animal-related injuries in a rural population in northeastern Turkey. Indian J Surg. 2013; 75(3): 200-3.

36. Busch HM Jr, Cogbill TH, Landercasper J, Landercasper BO. Blunt bovine and equine trauma. J Trauma. 1986; 26(6): 559-60.

37. Conrad L. The maul of the wild. Animal attacks can produce significant trauma. Emerg Med Serv. 1994; 23(3): 71-2, 76.

38. 1999 Severe animal attack and bite surveillance Summary. Texas Department of Health - Zoonosis Control Division.

39. Clifton M. Dog attack and maiming, US \& Canada September 1982 to November 13, 2006. http://www.dogsbite.org/ - accesed at the 5th of March 2015.

40. Garvey EM, Twitchell DK, Ragar R, Egan JC, Jamshidi R. Morbidity of pediatric dog bites: A case series at a level one pediatric trauma center. J Pediatr Surg. 2015; 50(2): 343-6.

41. Esposito S, Picciolli I, Semino M, Principi N. Dog and cat bite-associated infections in children. Eur J Clin Microbiol Infect Dis. 2013; 32(8): 971-6.

42. Gilyoma JM, Mabula JB, Chalya PL. Animal-related injuries in a resource-limited setting: experiences from a Tertiary health institution in northwestern Tanzania. World J Emerg Surg. 2013; 8(1): 7.

43. Chalya PL, Mchembe MD, Gilyoma JM, Mabula JB, Chandika AB, Mshana SE. Bite injuries at Bugando Medical Centre, Mwanza Tanzania: a five year experience. East Cent Afr J Surg. 2011; 16(1): 46-52.

44. Hagel L, Pahwa P, Dosman JA, Pickett W. Economic worry and the presence of safety hazards on farms. Accid Anal Prev. 2013; 53: 156-60. 